\title{
Globaaleja kriisejä, kosmopoliitteja visioita
}

Kosmopolitanismin käsite on ollut paljon esillä ihmistieteissä viime vuosina. Sen suosio näkyy myös kirjallisuudentutkimuksen puolella, missä on pohdittu kosmopoliitin romaanin erityispiirteitä (Schoene 2009) ja kosmopoliittia lukutapaa (Spencer 2011). Kosmopolitanismin kasvanut suosio näkyy myös siitä johdetuissa uusissa konsepteissa: esimerkiksi afrikkalaisen - eritoten afrodiasporisen - kirjallisuuden tutkimuksessa paljon keskustelua ja myös runsaasti kritiikkiä herättänyt afropolitanismi oli muutama vuosi sitten varsinainen muotikäsite.

Tyypillistä nykyisille kosmopolitanismi-keskusteluille on käsitteen demokratisointi ja laajentaminen. Perinteisesti kosmopolitanismiin onkin usein liitetty elitismin leima: se ymmärretään eliittien etuoikeutettuna, rajoja ylittävänä liikkeelläolona ja positiona, josta käsin toiseuden ymmärtäminen (ja kriittisestä näkökulmasta katsoen kuluttaminen) ja maailmassa "kotonaan oleminen" (Brennan 1997) on suhteellisen helppoa ja huoletonta. Puhutaan kosmopoliiteista; kosmopolitanismi siis nähdään identiteettipositiona, joka ihmisellä joko on tai ei ole. Toisinaan kosmopolitanismi saatetaan turhankin suoraviivaisesti yhdistää monikulttuurisiin metropoleihin, joissa kosmopolitanismin oletetaan "tapahtuvan" ikään kuin itsestään (Johansen 2014, 11-12). Todellisuudessa monia tällaisia näennäisen "kosmopoliitteja" kaupunkeja kuitenkin leimaa jakautuminen "etnisiin enklaaveihin" (Werbner 2015, 569-70) todellisten rajat ylittävien kohtaamisten sijaan: pelkkä visuaalinen heterogeenisyys ei toisin sanoen ole kosmopolitanismin tae.

Kosmopolitanismi onkin kenties hyödyllisempää ymmärtää väistämättä vaillinaisena ja jatkuvaa työtä vaativana asenteena, jossa keskeistä on avoimuus erilaisuudelle, rajat ylittävä ymmärrys maailmasta yhteisenä sekä oman position kriittinen tarkastelu globaalissa mittakaavassa. Kosmopolitanismin eettisutopistinen aspekti näyttäytyy nykymaailmassa usein käänteisesti kosmopolitanismin ideaalien epäonnistumisina ja rajoina (Stevic \& Tsang 2019). Globaalit kriisit, kuten ilmastonmuutos, pakolaisuus tai vaikkapa koronaviruspandeamia kuitenkin edellyttävät kosmopoliittia, rajat ylittävää näkökulmaa. Kirjallisuus on aivan erityinen väylä paitsi nykyhetkessä kosmopolitanismia horjuttavien ja estävien rakenteiden tarkasteluun ja kritisointiin, myös pienimuotoisten, käytännön kosmopolitanismin ilmentymien kuvaamiseen sekä kosmopoliitin tulevaisuuden kuvitteluun. Nämä kirjallisuuden "kosmopoliitit" roolit ja tasot nousevat esille useissa tämän numeron teksteissä.

Numeron avaa Jyrki Korpuan aiheeltaan ajankohtainen artikkeli "Wuhanista ja Sinisestä projektista Georgialaiseen: Virukset kauhun aiheuttajana dystopiafiktiossa”. Korpua sitoo virusteeman nykyhetkeen ja käsittelee virusten 
kerronnallisia funktioita kolmessa genrerajat ylittävässä kauhu- ja tieteisfiktion klassikkotekstissä. Dystopiafiktion kauhun aiheuttajina virukset pakottavat lukijan tarkastelemaan ympäröivää maailmaa ja toimivat varoituksena synkistä tulevaisuuden skenaarioista: mitä voisimme tehdä toisin?

Annukka Immosen artikkeli "Tunnekokemuksen metonyymisyys Sirkka Turkan runossa 'Syvällä metsässä nukkuu suuri hirvi'" keskittyy eksistentiaalisten tunteiden tarkasteluun runossa, jossa syntyy pienimuotoinen eettinen kohtaaminen ikkunasta piirtyvän luontomaiseman sulautuessa runon puhujan huoneeseen. Immosen analyysi tuo esille Turkan runon keinot kuvata kokemisen tapoja metonyymisyyden avulla ja korostaa sitä, kuinka tunteet muodostuvat runossa vuorovaikutteisessa suhteessa luontoon ja eläimiin.

Artikkelissaan "Apostrofisuuden ulottuvuuksia Paavo Rintalan romaanissa Sarmatian Orfeus" Päivikki Romppainen lukee Rintalan romaania "poissaolevan puhuttelun", apostrofin troopin kautta. Poissa olo on levinasilaisen eettisen suhteen olemus, jossa minä ei voi koskaan tavoittaa Toista, mutta jossa vastuullisuus syntyy puhutelluksi tulemisen kautta. Rintala jatkaa puhutteluketjua lukijan suuntaan, jolloin "parhaassa tapauksessa lukijassa syntyy reaktio, ehkä jopa teko, joka muuttaa, ellei maailmaa niin ainakin lukijaa itseään".

Numeron neljäs artikkeli tarkastelee lähilukemista. Kaisa Kortekallio ja Anna Ovaska pohtivat katsausartikkelissaan lähilukemisen ruumiillisia ja poliittisia ulottuvuuksia sekä lähilukemisen käytäntöjen sovellusmahdollisuuksia. Kirjoittajat myös tekevät näkyväksi lähilukemisen "vaihtoehtoista" historiaa, jossa lukijat on ymmärretty ruumiillisina ja maailmallisina olentoina.

Toni Lahtisen ja Panu Pihkalan dialogimuotoinen, sähköiseen kirjeenvaihtoon perustuva essee "Postikortteja Corona Ground Zerosta Helsinkiin: Huomioita pandemiasta ja ympäristökriisistä" tarttuu hienovaraisin sävyin globaaleihin kriiseihin. Esseessä kirjallisuudentutkija ja ympäristöahdistustutkija keskustelevat koronaviruksesta ja ilmastonmuutoksesta ja niiden yhteen kietoutuneisuudesta paitsi globaalista myös henkilökohtaisesta näkökulmasta.

Riitta Jytilän katsaus kartoittaa traumatutkimuksen uusia kysymyksenasetteluja, joissa korostuvat trauman moninaiset merkitykset ja ilmentymät kirjallisuudessa, ylirajaisuus, trauman estetiikka, sekä paikantumisen politiikka.

Puheenvuorossaan Lieven Ameel, Jussi Konttinen, Heidi Kuusisto, Iida Salonen ja Saku-Petteri Urpo kirjoittavat keväällä 2020 Turun yliopistossa järjestetyn "Toivoa tulevaisuudesta - Kaunokirjalliset tulevaisuusvisiot utopian kultakaudesta ilmastofiktioon" -kurssin aikana käydyistä keskusteluista kaunokirjallisuudessa kuvitelluista tulevaisuuksista.

Anne Rutasen esittelyssä on Suomen tietokirjailijat ry; kirjailija Sirpa Kähkönen puolestaan esittelee Suomen Kirjailijaliiton.

Kirja-arvioita on tässä numerossa kuusi. Kaisa Ilmosen arvioitavana on Uuden näytelmän antologia (toim. Helminen \& al., 2018). Tommi Dunderlin kirjoittaa Todd Andrew Borlikin toimittamasta kokoomateoksesta Literature and Nature in the English Renaissaince: An Ecocritical Anthology (2019), ja Anna 
Hollstenin arvio keskittyy Bo Carpelanin Urwind-romaania käsittelevään artikkelikokoelmaan Voicing Bo Carpelan: Urwind's Dialogic Possibilities (2020). Heidi Haapoja-Mäkelän käsittelyssä on Riikka Rossin monografia Alkukantaisuus ja tunteet: Primitivismi 1900-luvun alun suomalaisessa kirjallisuudessa (2020), ja Kuisma Korhonen arvioi kokoomateoksen Paperinen avaruus: Näkökulmia kirjaesineen ja kirjallisuuden materiaalisuuksiin (toim. Ahvenjärvi \&al., 2020). Esko Rahikaisen arvio käsittelee Sakari Katajamäen toimittamaa teosta Seitsemän veljestä ja opas sen lukemiseen (2020).

Käsissäsi oleva Avain on viimeinen nykyisten päätoimittajien voimin tehty numero. Seuraava numero eli 4/2020 on metsä-aiheinen teemanumero, jonka toimittavat vierailevat päätoimittajat Elsi Hyttinen ja Karoliina Lummaa. Vuoden 2021 alusta päätoimittajaparina toimivat Riitta Jytilä ja Lotta Kähkönen; toivotamme heidät tervetulleiksi Avaimeen! Kiitokset näistä kuluneesta kahdesta vuodesta, joiden aikana olemme lehteä toimittaneet. Erityiset kiitokset kuuluvat Avaimen kirjoittajille sekä arvioijille, jotka viime kädessä tekevät lehden.

\section{Anna-Leena Toivanen \& Joel Kuortti}

\section{Kirjallisuus}

Brennan, Timothy 1997. At Home in the World: Cosmopolitanism Now. Cambridge, MA: Harvard University Press.

Johansen, Emily 2014. Cosmopolitanism and Place: Spatial Forms in Contemporary Anglophone Literature. Basingstoke: Palgrave Macmillan.

Schoene, Berhold 2012. The Cosmopolitan Novel. Edinburgh: Edinburgh University Press.

Spencer, Robert 2011. Cosmopolitan Criticism and Postcolonial Literature. Basingstoke: Palgrave Macmillan.

Stevic, Aleksandar \& Philip Tsang, eds 2019. The Limits of Cosmopolitanism: Globalization and Its Discontents in Contemporary Literature. New York \& London: Routledge.

Werbner, Pnina 2015. The Dialectics of Urban Cosmopolitanism: Between Tolerance and Intolerance in Cities of Strangers. Identities: Clobal Studies in Culture and Power 22(1), 569-87. DOI: 10.1080/1070289X.2014.975712. 